Peer

Materials Science
Submitted 26 June 2020

Accepted 17 September 2020

Published 23 October 2020

Corresponding author

Sunil Karna, skarna@unionky.edu

Academic editor

Sasanka Deka

Additional Information and Declarations can be found on page 11

DOI 10.7717/peerj-matsci.10

Copyright

2020 Karna et al.

Distributed under

Creative Commons CC-BY 4.0

OPEN ACCESS

\section{Hydrothermal synthesis of carbon and sulfur mono-doped sodium tantalates}

\author{
Sunil Karna ${ }^{1}$, Christopher Saunders ${ }^{1}$, Roma Karna ${ }^{1}$, Deepa Guragain ${ }^{2}$, \\ Sanjay Mishra ${ }^{2}$ and Priya Karna ${ }^{3}$ \\ ${ }^{1}$ Department of Natural Science, Union College, Barbourville, KY, United States of America \\ ${ }^{2}$ Department of Physics, University of Memphis, Memphis, TN, United States of America \\ ${ }^{3}$ Department of Chemistry, University of Kentucky, Lexington, KY, United States of America
}

\section{ABSTRACT}

A set of experiments was conducted to synthesize doped and undoped sodium tantalates with carbon and sulfur in energy efficient single-step hydrothermal process. Undoped sodium tantalate nanocubes were synthesized at $140{ }^{\circ} \mathrm{C}$ and doped one at $180{ }^{\circ} \mathrm{C}$ for $12 \mathrm{~h}$ in rich alkaline atmosphere. The sizes of undoped, carbon-doped, and sulfurdoped sodium tantalate nanocubes were $38 \mathrm{~nm}, 45 \mathrm{~nm}$, and $40 \mathrm{~nm}$, respectively. The morphological, elemental, compositional, structural, thermal, and photophysical properties of as-synthesized doped and undoped sodium tantalate $\left(\mathrm{NaTaO}_{3}\right)$ were characterized using scanning electron microscope (SEM), energy dispersive $\mathrm{x}$-ray spectroscope (EDS), Raman spectroscopy, X-ray powder diffraction (XRD), thermal gravimetric analysis (TGA), Fourier transform infrared spectrophotometer (FTIR), and UV-vis spectrophotometer. The sulfur doped $\mathrm{NaTaO}_{3}$ shows a higher photocatalytic activity in degradation of methylene blue than carbon doped and the undoped $\mathrm{NaTaO}_{3}$. The band gaps of undoped $\mathrm{NaTaO}_{3}$, carbon doped $\mathrm{c}-\mathrm{NaTaO}_{3}$, and sulfur doped s$\mathrm{NaTaO}_{3}$ were calculated to be $3.94 \mathrm{eV}, 3.8 \mathrm{eV}$, and $3.52 \mathrm{eV}$, respectively using Tauc plot.

Subjects Catalysts, Energy Materials, Materials Science (other)

Keywords Perovskite, Metal oxide, Photocatalyst, Hydrothermal

\section{INTRODUCTION}

Sodium tantalates are perovskite compounds of sodium bonded with tantalum and oxygen atoms with definite proportion. A material that obeys the crystallographic structure of calcium titanate $\left(\mathrm{CaTiO}_{3}\right)$ is usually known as perovskite material. The perovskite structure (usually $\mathrm{ABC}_{3}$ type) simply consists of a large cation A with a 12-fold coordination at the center of a cubic lattice. The corners of the cube are relatively smaller cation $\mathrm{B}$ with 6 -fold coordination, and the midpoint of each edge are occupied by smaller anions $\mathrm{C}$ (halides or oxides). Alternately, large crystal system has cations A at corners, cation B at the center of the cube, and anions $\mathrm{C}$ or $\left(\mathrm{O}^{2-}\right)$ in the middle of each face as shown in Fig. 1 (Ward, 2005). In Fig. 1, Na stands for $\mathrm{A}$, Ta stands for $\mathrm{B}$, and $\mathrm{O}$ stands for $\mathrm{C}$. A unit cell of $\mathrm{NaTaO}_{3}$ shown in Fig. 1A has Ta at octahedron center and the Fig. $1 \mathrm{~B}$ has $\mathrm{Na}^{+}$shared with $12 \mathrm{O}^{-}$ions of 8 octahedra. Figure 1C is a probable molecular structure of sodium tantalate (Database, 2008). 
(A)

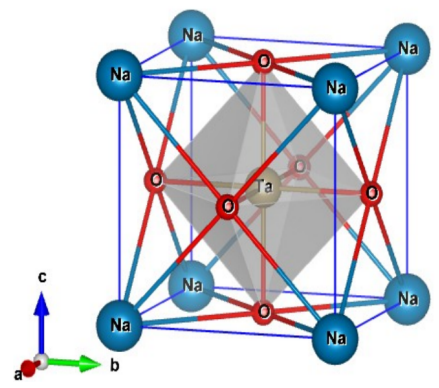

(B)

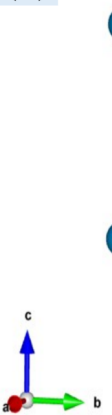

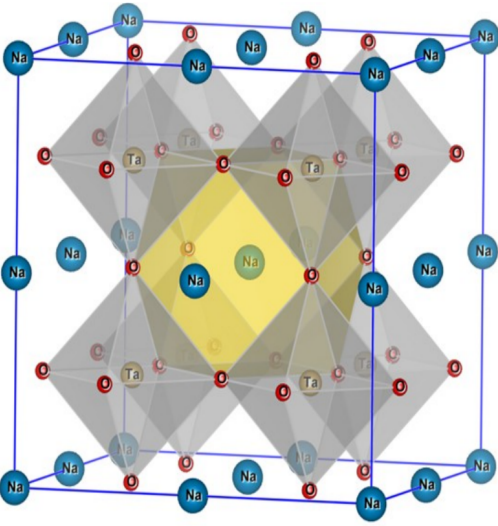

(C)

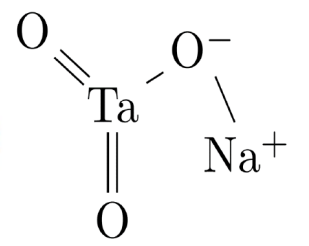

Figure 1 Perovskite crystal structure of $\mathrm{NaTaO}_{3}(\mathrm{~A})$, a 3D framework of corner sharing [ $\mathrm{TaO}_{6}$ ] octahedra with $\mathrm{Na}^{+}$ions in the twelve-fold cavities in between the polyhedral (B), and its molecular structure (C). Crystal structure of $\mathrm{NaTaO}_{3}$ was plotted using VESTA-software (Momma \& Izumi, 2011).

Full-size DOI: $10.7717 /$ peerjmatsci.10/fig-1

Perovskites with transition metal ions at site B exhibit interesting physical properties because of the distortion in crystals made by the dipole moment of central cation B (Ward, 2005; Johnsson \& Lemmens, 2007). The distortion in an ideal cubic form of perovskite resulted in orthorhombic, rhombohedral, hexagonal, and tetragonal forms. The structural evolution and change in electronic structure of a compound are responsible for their functional properties. These functionalities can be utilized in catalysis, fuel cells, and electrochemical sensing (Ward, 2005; Johnsson \& Lemmens, 2007; Gregory et al., 2002; Okoye, 2005; Atta, Galal \& El-Ads, 2016).

Metal oxide based nano perovskite exhibits a high activity for the photocatalytic decomposition of water and photodegradation of organic pollutants under ultraviolet irradiation, which could help minimize the environmental pollution and find alternative energy resources (Smith, 2013). The photocatalyst such as $\mathrm{NaTaO}_{3}$ utilizes only few fractions of visible light spectrum for useful work because of its wide band gap of about $4 \mathrm{eV}$. Fortunately, it has been observed that the features of $\mathrm{NaTaO}_{3}$ can be tuned by doping of cations or anions into the stoichiometric phase of its base structure to change its physical and chemical behavior (Li \& Zang, 2009; Kang \& Park, 2010; Li et al., 2015; Kanhere \& Chen, 2014; Lan et al., 2015). Doping of metal cations or anions on $\mathrm{NaTaO}_{3}$ reduces its band gap and enhances the visible light response. The process of cation doping on $\mathrm{NaTaO}_{3}$ are, however, a bit complicated and would limit the economical utilization of the photocatalyst (Kang \& Park, 2010; Li et al., 2015). Anion doping into the oxygen site of metal oxides can be useful and easily controlled during synthesis process. Thus, photocatalytic activities of $\mathrm{NaTaO}_{3}$ can also be enhanced by doping of non-metal anions such as nitrogen, sulfur, or carbon (Kanhere \& Chen, 2014; Lan et al., 2015; Liu et al., 2019; Shi \& Guo, 2012; Kudo et al., 2007; Fu et al., 2008). The doping of anions in metal oxides forms an acceptor level because of its electronegativity which increases the valance band-edge potential and thus reduces the band gap. The band gap of the metal oxides reduces significantly if the dopant has $\mathrm{P}$-orbital energy higher than the $\mathrm{O}_{2 \mathrm{P}}$ orbitals 
(Li et al., 2015). The sulfur has low electronegativity than oxygen, but a higher electron affinity due to its larger size. Sulfur is also a divalent atom that can replace oxygen atom at substitutional site. Such property of sulfur makes it an efficient dopant of $\mathrm{NaTaO}_{3}$. Carbon is also less electronegative than oxygen, but it can contribute more holes in valance band. The $\mathrm{C}$ dopants promote separation of photogenerated electrons-holes and thus reduce the rate of recombination (Lavand \& Malghe, 2015). The S and C are thus considered to be promising dopants for visible light induced photocatalysis. It has also been reported that the dopant like $\mathrm{N}$ (nitrogen) leaves excessive numbers of holes in valance band which forms the recombination centers for electron-hole trapping, thus reduces the lifespan of photogenerated charge carriers (Wang et al., 2013).

Appreciable amount of work has been done in mono-doping or co-doping of $\mathrm{NaTaO}_{3}$ with dopants like $\mathrm{La}, \mathrm{Co}, \mathrm{Sm}, \mathrm{Bi}, \mathrm{N}, \mathrm{P}$, and F but a very little work has been devoted to the $\mathrm{C}$ or $\mathrm{S}$ doping. Hence, through this experiment we have synthesized and doped sodium tantalates $\left(\mathrm{NaTaO}_{3}\right)$ with $\mathrm{C}$ and $\mathrm{S}$ to study their comparative photophysical properties. An environmental-friendly low temperature chemical process has been used to synthesize all the samples in this study. In order to optimize growth parameters of the nanostructures we have characterized them for morphological, compositional, structural, thermal, and optical properties using SEM, EDS, Raman, FTIR, XRD, TGA, and UV-Vis Spectroscopy.

\section{MATERIALS \& METHODS Materials synthesis}

There are various factors that affect the structure of perovskite crystals such as increase of temperature, particle size, tiltation of octahedral, synthesis process, concentration of reaction mixture, and reaction time (Ahmad, Farooq \& Phul, 2018). Various methods have already been developed to synthesize perovskite materials such as ball milling, thermal evaporation, sol-gel process, and hydrothermal process (Ward, 2005). Among all these processes, hydrothermal process is one of the most suitable chemical processes in terms of energy consumption and environmental friendliness for the varieties of perovskite compounds. Size and chemical compositions of oxides type perovskite in hydrothermal process (HTs) can be controlled by adjusting the concentration of precursors, reaction time, and temperature. This process is based on a dissolution/precipitation mechanism. We have used a low temperature HTs to synthesize and dope sodium tantalates $\left(\mathrm{NaTaO}_{3}\right)$ by optimizing the concentration of the reactant precursors.

The $\mathrm{NaTaO}_{3}$ perovskite were synthesized by reacting tantalum penta-oxide precursor $\mathrm{Ta}_{2} \mathrm{O}_{5}$ in high alkaline environment $\mathrm{NaOH}$ under hydrothermal conditions at low temperature. The reaction mechanism is given as

$2 \mathrm{NaOH}+\mathrm{Ta}_{2} \mathrm{O}_{5} \stackrel{t^{\circ} \mathrm{C}}{\longrightarrow} 2 \mathrm{NaTaO}_{3}+\mathrm{H}_{2} \mathrm{O}$.

For sodium tantalate $\left(\mathrm{NaTaO}_{3}\right), 0.442 \mathrm{~g}$ of $\mathrm{Ta}_{2} \mathrm{O}_{5}$ powder was dissolved in $0.75 \mathrm{M}$ of $\mathrm{NaOH}$ for $5 \mathrm{~h}$ with magnetic stirring. The $50 \mathrm{~mL}$ solution was then kept in a $100 \mathrm{~mL}$ capacity teflon lined autoclave and heated for $12 \mathrm{~h}$ at $140^{\circ} \mathrm{C}$ ( $\mathrm{Li} \& \mathrm{Zang}$, 2009). The autoclaves were naturally cooled down to the room temperature before milky-white product was collected, centrifuged washed with water and ethanol many times, and dried at $80^{\circ} \mathrm{C}$ overnight. 
For C-doped sodium tantalate $\left(\mathrm{c}-\mathrm{NaTaO}_{3}\right), 2 \mathrm{~g}$ of glucose $\left(\mathrm{C}_{6} \mathrm{H}_{12} \mathrm{O}_{6}\right)$ was dispersed in a mixture of $30 \mathrm{ml}$ deionized water and $20 \mathrm{ml}$ polyethelene glycol (400) for $15 \mathrm{~min}$ with ultrasonication. Then, $1.5 \mathrm{~g}(0.75 \mathrm{M})$ of $\mathrm{NaOH}$ and $0.442 \mathrm{~g}$ of $\mathrm{Ta}_{2} \mathrm{O}_{5}$ powder were added in the mixture and stirred on a magnetic stirrer for $5 \mathrm{~h}$. The solution was then kept in teflon lined autoclave and heated for $12 \mathrm{~h}$ at $180^{\circ} \mathrm{C}$ (Kang \& Park, 2010; Wu et al., 2014). The same cleaning procedure as above was used to collect light-brownish product.

For S-doped sodium tantalate $\left(\mathrm{s}-\mathrm{NaTaO}_{3}\right), 0.442 \mathrm{~g}$ of $\mathrm{Ta}_{2} \mathrm{O}_{5}$ powder and $0.200 \mathrm{~g}$ of sodium thiosulfate $\left(\mathrm{Na}_{2} \mathrm{~S}_{2} \mathrm{O}_{3}: 5 \mathrm{H}_{2} \mathrm{O}\right)$ were dissolved in $1.5 \mathrm{~g}$ of $\mathrm{NaOH}$ and $50 \mathrm{ml}$ deionized water by magnetic stirring for $5 \mathrm{~h}$ and $5 \mathrm{~min}$ of ultrasonication. The solution was then kept in teflon lined autoclave and heated for $12 \mathrm{~h}$ at $180^{\circ} \mathrm{C}$ (Li et al., 2015). The same cleaning procedure as previous cases was used to collect white product. The reagent grade tantalum pentaoxide powder bought from Sigma Aldric was used in this experiment.

\section{Photocatalytic test}

The photocatalytic activities of doped and undoped $\mathrm{NaTaO}_{3}$ were evaluated by degrading aqueous solution of methylene blue (MB) in visible light irradiation. The photo reactor chamber was locally improvised where the solution was kept cool using water circulating jacketed beaker of $100 \mathrm{ml}$ and was being magnetically stirred during the process. The stock solution of methylene blue of concentration $20 \mathrm{mg} / \mathrm{L}$ was prepared by dissolving $20 \mathrm{mg}$ of methylene blue powder in 11 of deionized water and stored in dark room for future use.

As synthesized photocatalyst powder of $0.05 \mathrm{~g}$ was dispersed in $50 \mathrm{ml}$ of 20 $\mathrm{mg} / \mathrm{L}$ concentrated methylene blue (MB) aqueous solution. The suspension was then ultrasonicated for $10 \mathrm{~min}$ and stored in dark for $30 \mathrm{~min}$ to allow adsorption-desorption equilibrium between photocatalyst and the MB. The suspension was being stirred magnetically and kept cool during this process. The white light LED of $50 \mathrm{~W}$ was taken as a source of visible light and was kept at about $20 \mathrm{~cm}$ above the solution. The suspensions and the aqueous MB solution were kept in dark for $30 \mathrm{~min}$. The UV/Vis spectra of these solutions were taken before and after visible light irradiation. At every $50 \mathrm{~min}$ of irradiation about $2 \mathrm{ml}$ of solution was withdrawn from the reactor cell (beaker), centrifuged for $10 \mathrm{~min}$ at $3000 \mathrm{rpm}$ and the supernatant of the solution was taken for UV/Vis spectrum. The percentage photo degradation, $\eta$ of $\mathrm{MB}$ was taken as

$\eta=\frac{A}{A_{o}} \times 100 \%$

where $A_{o}$ is the absorbance before irradiation, and $A$ is the absorbance obtained after every 50 min of irradiation of sample in visible light. The intensity of light on the exposed surface of $\mathrm{MB}$ was calculated to be about $10 \mathrm{~mW} / \mathrm{cm}^{2}$.

\section{RESULTS AND DISCUSSION}

The table-top scanning electron microscope (SEM) was used to study the morphology of the samples. The cubic morphology of undoped and doped nanostructures is shown in Figs. 2A-2C. The morphology of the samples seem similar may be because of the range of doping is very little as can be depicted by XRD of the samples. However, the morphology 

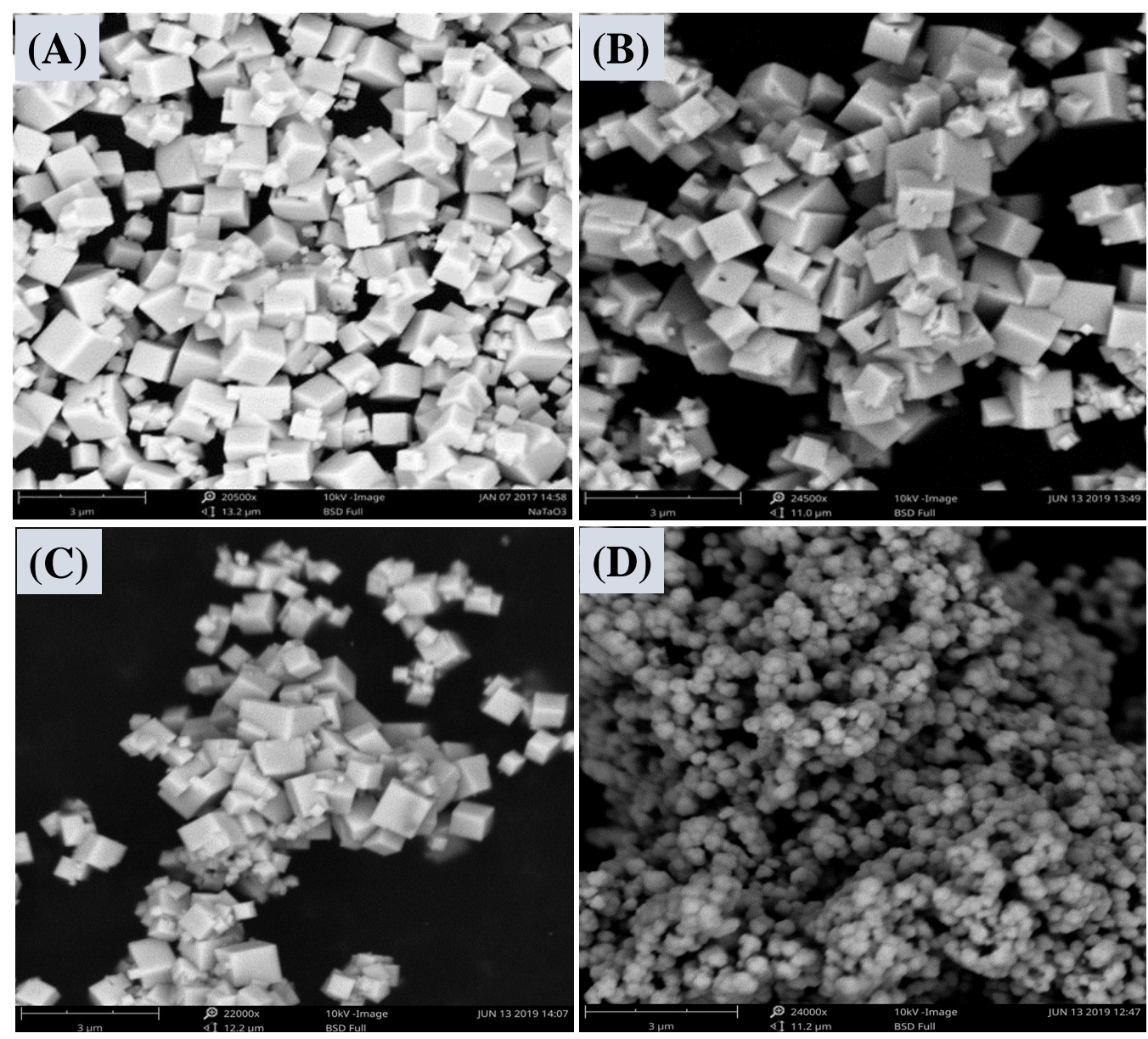

Figure 2 SEM images of the pure $\mathrm{NaTaO}_{3}(\mathrm{~A}), \mathrm{c}-\mathrm{NaTaO} 3(\mathrm{~B}), \mathrm{s}-\mathrm{NaTaO}_{3}(\mathrm{C})$, and c-NaTaO${ }_{3}$ without glucose as a reaction component $(\mathrm{D})$.

Full-size D DOI: 10.7717/peerjmatsci.10/fig-2

of carbon doped sodium tantalates without using glucose in a reaction mixture along with ethylene glycol during synthesis is shown in Fig. 2D.

The compositions of catalyst are shown in Fig. 3 by the EDS images. The plot indicates presence of dopants such as Sulfur and Carbon effectively incorporated into the sodium tantalate matrix during hydrothermal process.

Raman spectra were taken to verify EDS and XRD study. The bands between 400 to $1,100 \mathrm{~cm}^{-1}$ related to the internal vibrational mode of $\mathrm{Ta}_{2} \mathrm{O}_{6}$ in $\mathrm{NaTaO}_{3}$ structure (Vishnu et al., 2008; Hernandez, Flores \& Martinez, 2018). The major bands at 450, 500, 620, and $720 \mathrm{~cm}^{-1}$ in $\mathrm{NaTaO}_{3}$ are reported earlier (Longjie \& Hiroshi, 2015). One additional band appeared at $860 \mathrm{~cm}^{-1}$ which is associated with doping of sulfur and may be related to the phase transition of $\mathrm{Ta}_{2} \mathrm{O}_{6}$ octahedra tiltation as shown in Fig. 4A. In Fig. 4B, the broad mask between 1,100 to $1,800 \mathrm{~cm}^{-1}$ engulfing the characteristics $\mathrm{D}$ and $\mathrm{G}$ bands is related to the amorphous carbon and explains the formation of composite between carbon and 


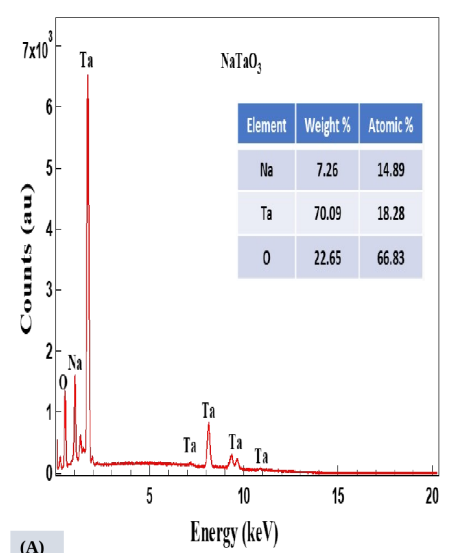

(A)

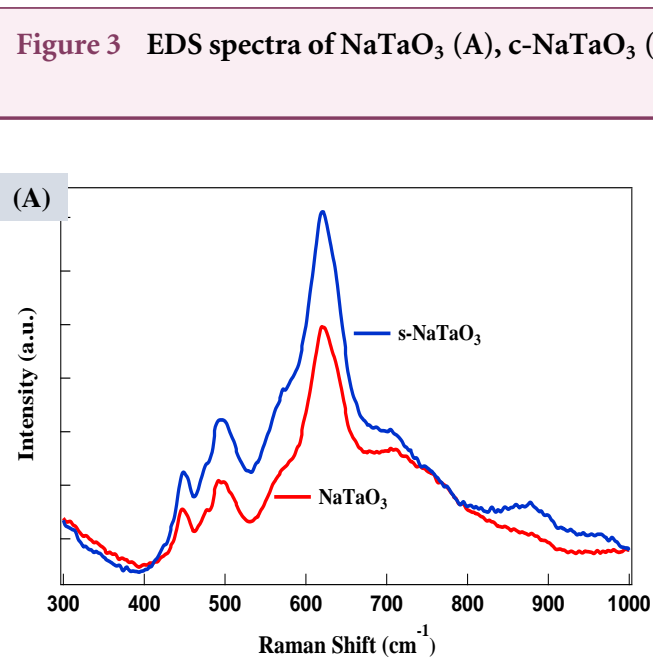

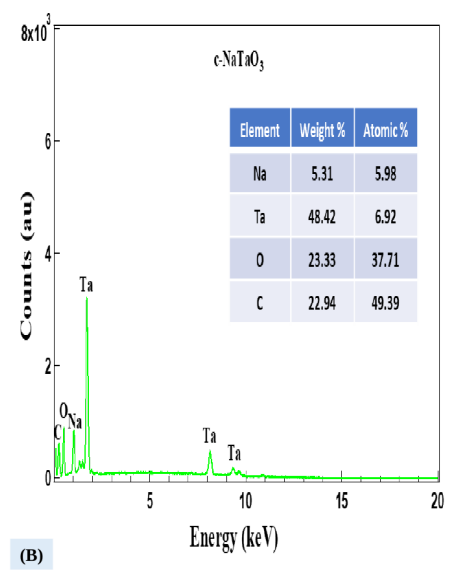

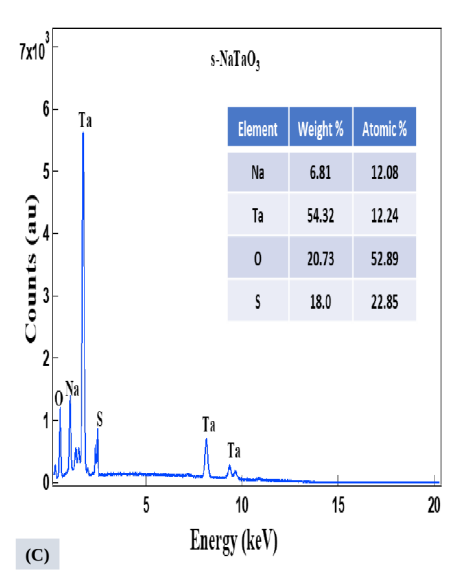

Full-size日DOI: $10.7717 /$ peerjmatsci.10/fig-3

Figure 4 Raman spectra of $(\mathrm{A}) \mathrm{NaTaO}_{3}$ and $\mathrm{s}-\mathrm{NaTaO}_{3}$ and (B) $\mathrm{c}-\mathrm{NaTaO}_{3}$ samples. Full-size DOI: 10.7717/peerjmatsci.10/fig-4

$\mathrm{NaTaO}_{3}$ (Hernandez, Flores \& Martinez, 2018). The excessive amount of carbon in host material acts as a recombination center and reduces the photocatalytic activity.

Bruker D8 Advance X-ray Diffractometer was used to collect X-ray diffraction patterns. XRD patterns of sodium tantalate $\left(\mathrm{NaTaO}_{3}\right)$ crystals along with their Rietveld refinement profiles are shown in Figs. 5A and 5B. The observed and calculated XRD profiles of $\mathrm{NaTaO}_{3}$ with the help of crystallography open database (COD) are seen in fair agreement with each other and suggests single phase compounds of cubic perovskite structure with space group Pm-3m (\#221). The lattice parameters, space group, and atomistic positions were analyzed using Rex, Maud, and PowderX software from observed XRD data. The crystal data and refinement factors of the sample $\mathrm{NT}\left(\mathrm{NaTaO}_{3}\right)$ are summarized as Lattice Parameters: $a=b=c=3.89002 \AA, \alpha=\beta=\gamma=90^{\circ}, \mathrm{R}_{\mathrm{p}}=0.16, \mathrm{R}_{\mathrm{wp}}=0.23, \mathrm{R}_{\exp }=0.18$, and $\mathrm{GoF}$ $=1.27$. Undoped $\left(\mathrm{NaTaO}_{3}\right)$, carbon doped $\left(\mathrm{c}-\mathrm{NaTaO}_{3}\right)$, and sulfur doped $\left(\mathrm{s}-\mathrm{NaTaO}_{3}\right)$ sodium tantalates are shown in Fig. $5 \mathrm{C}$ with inset showing prominent peaks are slightly shifted towards lower $2 \theta$ angle as doped. However, C-doped sample has not shown any 

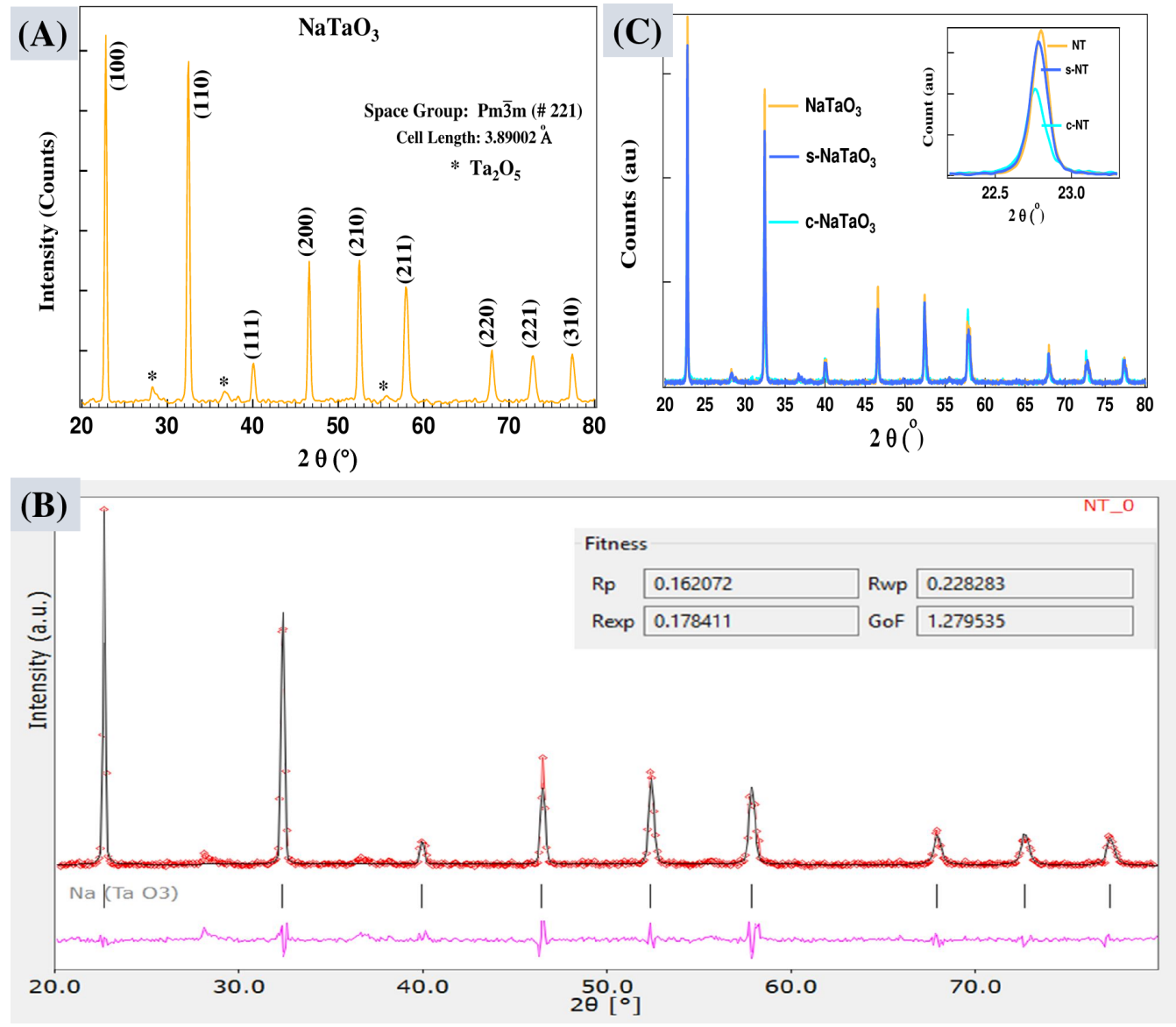

Figure 5 XRD patterns of $\mathrm{NaTaO}_{3}(\mathrm{~A})$, Rietveld refinement profile of the sample NT using Rex software. Experimental pattern (red), calculated data fit (cyan), and difference curve are shown in pink in the refined data $(B)$, XRD pattern of all the samples.

Full-size DOI: 10.7717/peerjmatsci.10/fig-5

noticeable shift which could be due to formation of amorphous carbon in the host materials as can be verified by Fig. 4B. The crystal data and refinement factors of the sample c-NT (c$\left.\mathrm{NaTaO}_{3}\right)$ are $a=b=c=3.90262 \AA, \alpha=\beta=\gamma=90^{\circ}, \mathrm{R}_{\mathrm{p}}=0.27, \mathrm{R}_{\mathrm{wp}}=0.39, \mathrm{R}_{\exp }=0.30$, and $\mathrm{GoF}=1.28$, and that of s-NT $\left(\mathrm{s}-\mathrm{NaTaO}_{3}\right)$ are $a=b=\mathrm{c}=3.89830 \AA, \alpha=\beta=\gamma=90^{\circ}$, $\mathrm{R}_{\mathrm{p}}=0.28, \mathrm{R}_{\mathrm{wp}}=0.47, \mathrm{R}_{\exp }=0.30$, and $\mathrm{GoF}=1.53$, respectively.

The average crystallites sizes (L) of $\mathrm{NaTaO}_{3}, \mathrm{~s}-\mathrm{NaTaO}_{3}$, and c- $\mathrm{NaTaO}_{3}$ are $38 \mathrm{~nm}, 40$ $\mathrm{nm}$, and $45 \mathrm{~nm}$, respectively as measured from full width at half maximum (FWHM) of prominent XRD peaks at about $32^{\circ}$ of $2 \theta$ peak position using Scherrer's formula (Langford \& Wilson, 1978),

$L=\frac{K \lambda}{\beta \cos (\theta)}$,

where $K=0.89$ for cubical symmetry, FWHM $(\beta)$ at $2 \theta$ in radian unit, and $\lambda=0.1540598$ $\mathrm{nm}$. XRD data indicates highly crystalline cubic nanoparticles with d value of (100) plane is about $0.3903 \mathrm{~nm}$. A detailed inspection of peaks displays the slight shift of position 

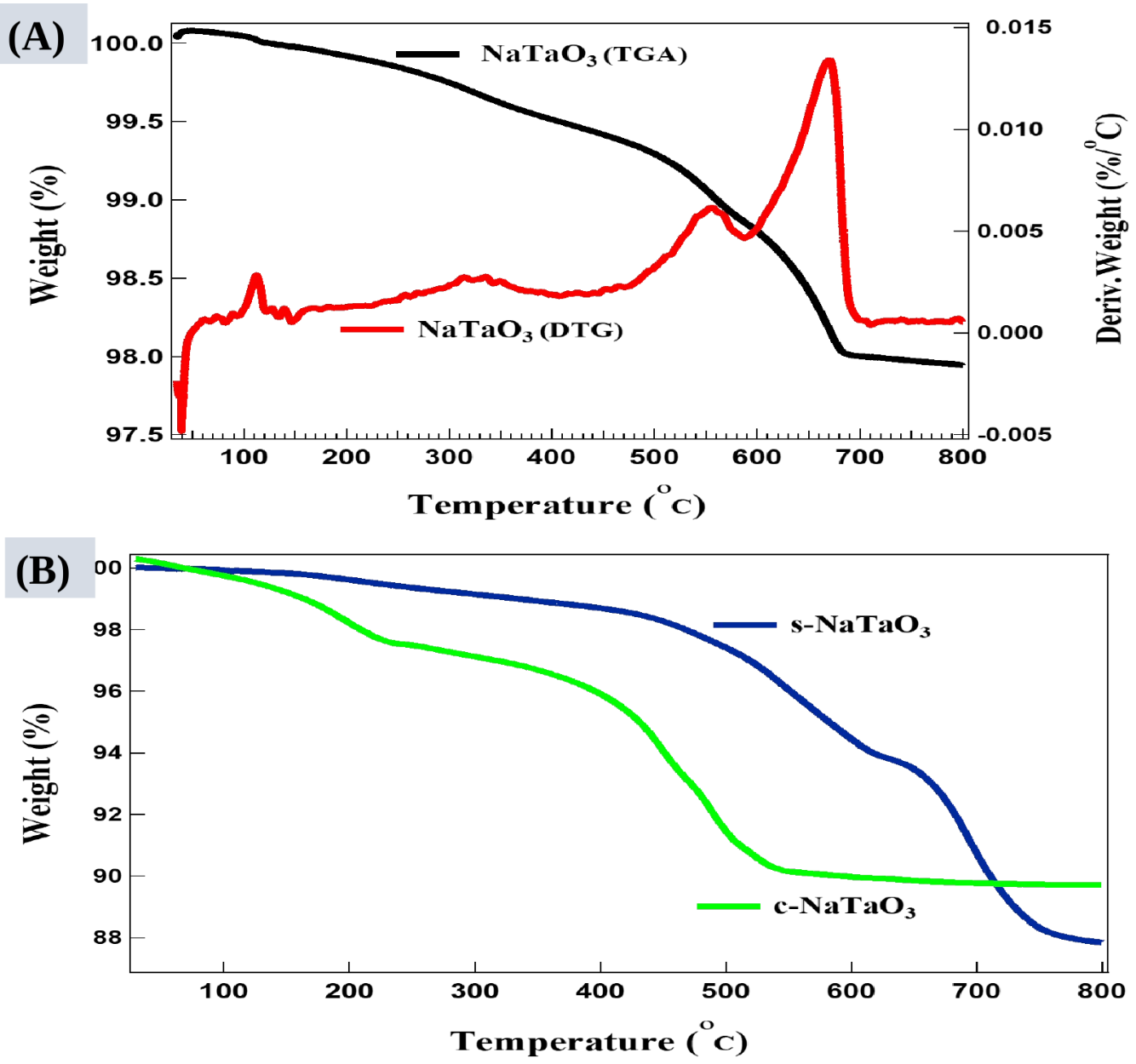

Figure 6 TGA/DTG curves of $\mathrm{NaTaO} 3$ (A), c-NaTaO3 and s-NaTaO3 (B). .

Full-size DOI: $10.7717 /$ peerjmatsci.10/fig-6

towards lower angle in doped samples, indicating the tendency of modifying cubic phase of $\mathrm{NaTaO}_{3}$ crystal.

TGA curves were obtained in nitrogen atmosphere at a heating rate of $10{ }^{\circ} \mathrm{C} / \mathrm{min}$ as shown in Fig. 6. TGA curve determines thermal stability and monitors decomposition behavior of synthesized nanocubes. Each sample produces different sigmoidal shapes of TGA curves. Gradual but slow weight loss up to $150^{\circ} \mathrm{C}$ indicates dehydration and evaporation of volatile contents in the sample (such as residual ethanol contents from cleaning). A little incremental weight below $100{ }^{\circ} \mathrm{C}$ may be due to buoyancy effect of atmosphere inside the TG system. The samples were hygroscopic in nature due to the synthesis process, and it is expected to have weight loss below $200{ }^{\circ} \mathrm{C}$. The higher weight loss was observed between $300-700{ }^{\circ} \mathrm{C}$ associated with residual low molecular weight substance, decomposition reaction, and coordinated water elimination. Since TGA curves are dependent on heating rate hence any experimental parameters that effect the reaction rate will change the shape of curve e.g., type of materials, purge gas, sample mass, volume, and morphology (Froberg, 2020). Sodium tantalate, $\mathrm{NaTaO}_{3}$ sample has shown very little 


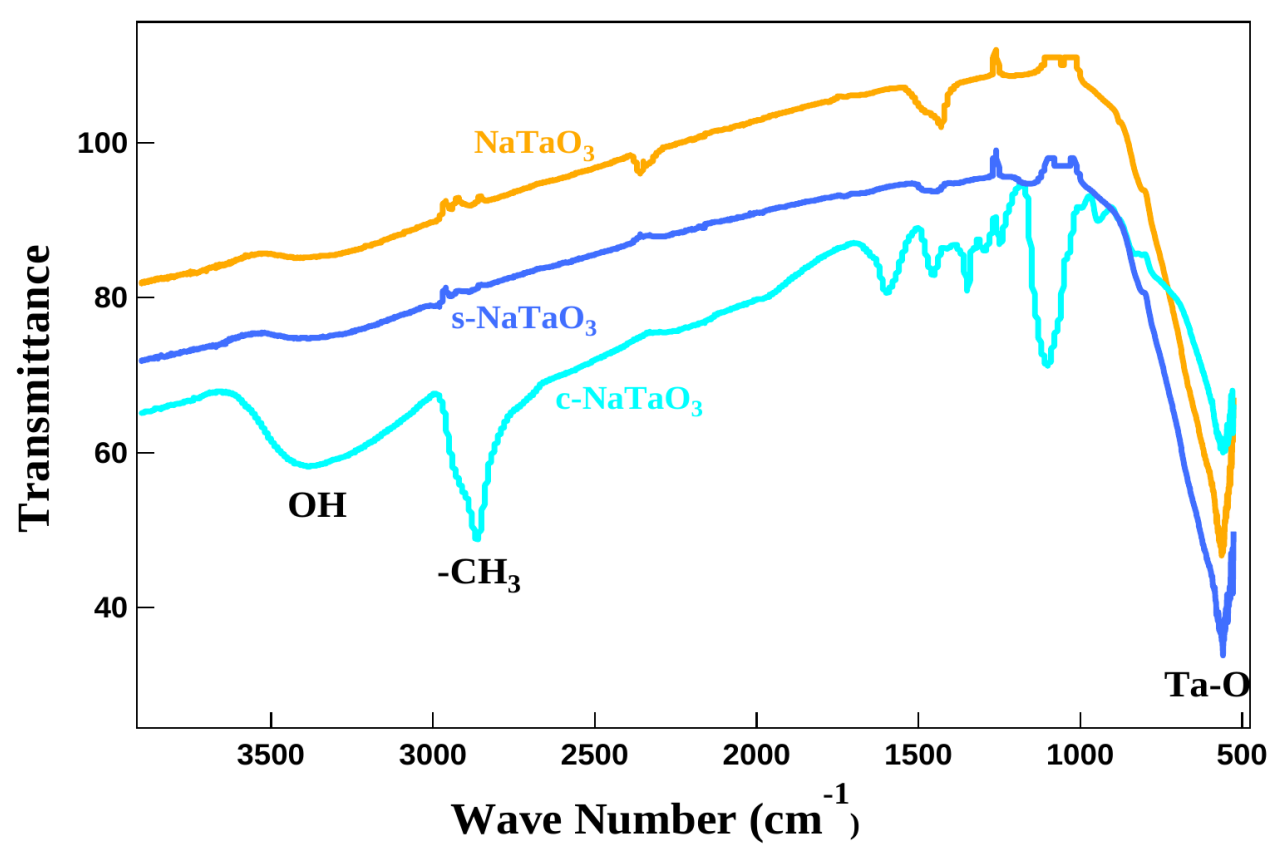

Figure 7 FTIR curves of doped and undoped NaTaO3. The plot is offset by 10 points for clarity. Full-size DOI: 10.7717 / peerjmatsci.10/fig-7

weight loss altogether of about $2.37 \%$. The first derivative of TGA curve (DTG) reveals several steps of mass loss. The DTG curve shows that $0.87 \%$ and $0.52 \%$ mass loss happen at $660{ }^{\circ} \mathrm{C}$ and $550{ }^{\circ} \mathrm{C}$, respectively. The peak at $110^{\circ} \mathrm{C}$ corresponds to evaporation of volatiles as shown in Fig. 6A. The TGA of s- $\mathrm{NaTaO}_{3}$ and $\mathrm{c}-\mathrm{NaTaO}_{3}$ samples in Fig. $6 \mathrm{~B}$ has shown the high degradation of impurities from sodium thiosulphate residue and the glucose residue and cause their weight loss of about $12.4 \%$ and $10 \%$, respectively. The c- $\mathrm{NaTaO}_{3}$ also shows oxidation process between $250{ }^{\circ} \mathrm{C}$ to $460{ }^{\circ} \mathrm{C}$ and become thermally stable after $560^{\circ} \mathrm{C}$.

Figure 7 shows FTIR spectra of as synthesized samples. The spectrum of $\mathrm{NaTaO}_{3}$ comprises of a strong band at $560 \mathrm{~cm}^{-1}$ which corresponds to $\mathrm{Ta}-\mathrm{O}$ stretching bond. The spectrum of s- $\mathrm{NaTaO}_{3}$ displays similar spectrum as undoped $\mathrm{NaTaO}_{3}$ without any bands related to $\mathrm{SO}_{3}{ }^{2-}$ or $\mathrm{SO}_{4}{ }^{2}$ - indicating no residue of sulfur during washing. The bands around 1,000 to $1,630 \mathrm{~cm}^{-1}$ corresponds to $\mathrm{Na}$ - O vibrations. A broad peak around 3,400-3,500 $\mathrm{cm}^{-1}$ corresponds to $\mathrm{H}_{2} \mathrm{O}$ bands and strong stretching modes of the $\mathrm{O}-\mathrm{H}$ band. The intense peak at $1,068 \mathrm{~cm}^{-1}$ corresponds to $\mathrm{CO}_{3}{ }^{-2}$ vibration band in spectrum of c- $\mathrm{NaTaO}_{3}$ (Li et al., 2015).

The visible light photo degradation of $\mathrm{MB}$ was analyzed using UV/Vis spectrometer. The peak at $664 \mathrm{~nm}$ was chosen to study the degradation of MB with and without catalysts and has been shown in Fig. 8A. Not an appreciable change has been observed in UV/Vis spectra of blank MB solution after keeping 30 min in dark, depicting the reaching of the adsorption desorption equilibrium. The photoactivity of blank MB solution was very low, only $1.7 \%$ degradation was observed after $300 \mathrm{~min}$. The degradation of $\mathrm{MB}$ and other dyes in visible light photolysis has been reported by previous authors (Esparza et al., 2020; 

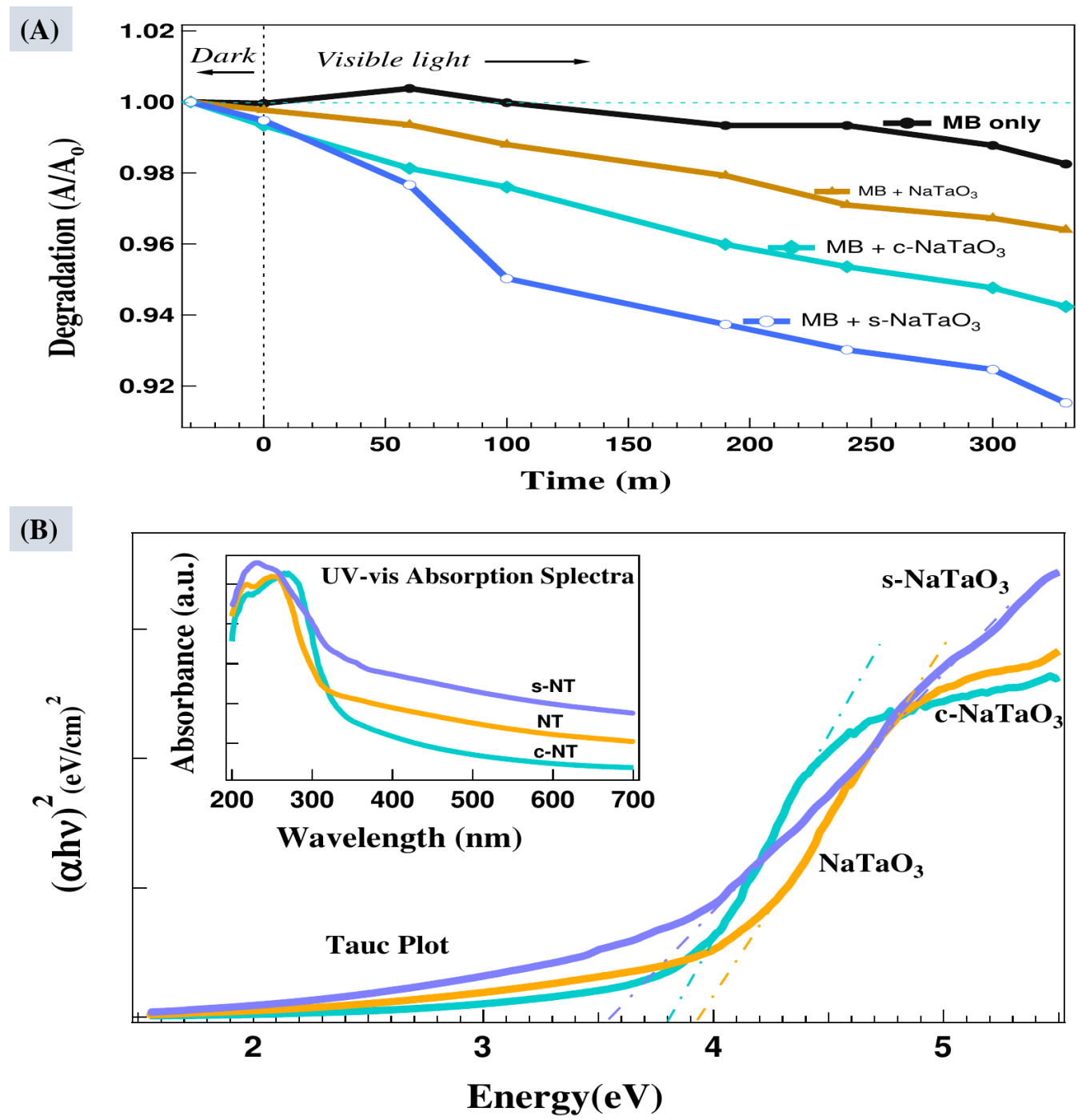

Figure 8 Photodegradation of methylene blue (MB) in solution containing $\mathrm{NaTaO}_{3}, \mathrm{c}-\mathrm{NaTaO}_{3}$, and s-NaTaO ${ }_{3}$ catalysts (A), and Tauc plot with inset UV-vis diffused reflectance spectra of all the samples (C).

Full-size DOI: 10.7717/peerjmatsci.10/fig-8

Li et al., 2015; Lan et al., 2015; Hou, Hu \& Zhu, 2018; Lavand \& Malghe, 2015; Khaneghah, Yangjeh \& Abedi, 2018). The $\mathrm{MB}$ with catalysts $\mathrm{NaTaO}_{3}, \mathrm{c}-\mathrm{NaTaO}_{3}$, and $\mathrm{s}-\mathrm{NaTaO}_{3}$ has shown $3.4 \%, 5.1 \%$, and $7.8 \%$ degradation, respectively within $300 \mathrm{~min}$ of visible light irradiation. Due to large optical band gap of these catalysts and consequently very poor absorption of visible light its degradation efficiency was very poor. Figure $8 \mathrm{~B}$ shows the UV/Vis absorption spectra of $\mathrm{NaTaO}_{3}, \mathrm{c}-\mathrm{NaTaO}_{3}$, and s- $\mathrm{NaTaO}_{3}$ catalysts. The Tauc plot of $(\alpha \mathrm{h} v)^{2}$ ploted against energy from UV/vis diffused reflectance spectra shows the photocatalysts $\mathrm{NaTaO}_{3}, \mathrm{c}-\mathrm{NaTaO}_{3}$, and s- $\mathrm{NaTaO}_{3}$ have direct band gap energy of $3.94 \mathrm{eV}$, $3.8 \mathrm{eV}$, and $3.52 \mathrm{eV}$, respectively. 


\section{CONCLUSIONS}

Sulfur and carbon mono-doped sodium tantalate nanocubes were grown successfully in rich alkaline atmosphere by low temperature hydrothermal process. The sodium tantalate $\left(\mathrm{NaTaO}_{3}\right)$, carbon doped sodium tantalate $\left(\mathrm{c}-\mathrm{NaTaO}_{3}\right)$, and sulfur doped sodium tantalate $\left(\mathrm{s}-\mathrm{NaTaO}_{3}\right)$ have found perovskite crystal structure of $\mathrm{Pm}-3 \mathrm{~m}$ cubic phase with an average size of $38 \mathrm{~nm}, 45 \mathrm{~nm}$, and $40 \mathrm{~nm}$, and their band gaps were calculated as $3.94 \mathrm{eV}, 3.8 \mathrm{eV}$, and $3.52 \mathrm{eV}$, respectively. The slight shift in prominent XRD peaks position of S-doped $\mathrm{NaTaO}_{3}$ are found towards lower angle but no noticeable shift has been observed in C-doped $\mathrm{NaTaO}_{3}$. Bandgap of S-doped $\mathrm{NaTaO}_{3}$ is found narrower than C-doped and undoped $\mathrm{NaTaO}_{3}$. S-doped $\mathrm{NaTaO}_{3}$ shows comparatively higher visible light photocatalytic activity than C-doped and undoped $\mathrm{NaTaO}_{3}$. Due to high band gap the photocatalytic activities of these photocatalysts were poor, however, enhancement in adsorption of methylene blue solution has been observed with the use of these photocatalysts.

\section{ACKNOWLEDGEMENTS}

We would like to thank Department of Natural Science and the Physical Plant of Union College for their support in this project.

\section{ADDITIONAL INFORMATION AND DECLARATIONS}

\section{Funding}

This work was supported by the Faculty Research Committee, and Title III grant, Union College, Barbourville, KY. The funders had no role in study design, data collection and analysis, decision to publish, or preparation of the manuscript.

\section{Grant Disclosures}

The following grant information was disclosed by the authors:

The Faculty Research Committee, and Title III grant, Union College, Barbourville, KY.

\section{Competing Interests}

The authors declare there are no competing interests.

\section{Author Contributions}

- Sunil Karna conceived and designed the experiments, analyzed the data, prepared figures and/or tables, authored or reviewed drafts of the paper, and approved the final draft.

- Christopher Saunders performed the experiments, prepared figures and/or tables, and approved the final draft.

- Roma Karna performed the experiments, prepared figures and/or tables, authored or reviewed drafts of the paper, and approved the final draft.

- Deepa Guragain performed the experiments, prepared figures and/or tables, and approved the final draft.

- Sanjay Mishra analyzed the data, authored or reviewed drafts of the paper, and approved the final draft. 
- Priya Karna performed the experiments, authored or reviewed drafts of the paper, and approved the final draft.

\section{Data Availability}

The following information was supplied regarding data availability:

The raw measurements are available in the Supplemental Files.

\section{Supplemental Information}

Supplemental information for this article can be found online at http://dx.doi.org/10.7717/ peerj-matsci.10\#supplemental-information.

\section{REFERENCES}

Ahmad T, Farooq U, Phul R. 2018. Fabrication and photocatalytic applications of perovskite materials with special emphasis on alkali-metal-based niobates and tantalates. Industrial \& Engineering Chemistry Research 1:18-41 DOI 10.1021/acs.iecr.7b04641.

Atta N, Galal A, El-Ads EH. 2016. Perovskite nanomaterials-synthesis, characterization, and applications. Intech Ch 4:108-113 DOI 10.5772/61280.

Esparza MA, Rivera LP, Centeno A, Ojeda A, González DR, Chávez A, Aranda MA, Cruz J, Galván JG. 2020. UV and Visible light photodegradation of methylene blue with graphene decorated titanium dioxide. Materials Research Express 7(3):035504 DOI 10.1088/2053-1591/ab7ac5.

Froberg L. 2020. Lecture on thermal analysis TGA/DTA. Turku: Process Chemistry Center, ABO Akademi University. Available at http://web.abo.fi/instut/biofuelsGS2/kursen/\%C5A/lectures/Lectrure_Thermal\%20Analysis.pdf.

Fu H, Zhang S, Zhang L, Zhu Y. 2008. Visible-light-driven natao3-xnx catalyst prepared by hydrothermal process. Materials Research Bulletin 43:864-872 DOI 10.1016/j.materresbull.2007.05.013.

Gregory KLG, Sossina MH, Carlos GL, Fred FL. 2002. Hydrothermal synthesis of perovskite and pyrochlore, powders of potassium tantalate. Journal of Materials Research 17(12):3168-3176 DOI 10.1557/JMR.2002.0458.

Hernandez JM, Flores AM, Martinez LM. 2018. Photoelectrocatalytic characterization of carbon-doped $\mathrm{NaTaO}_{3}$ applied in the photoreduction of $\mathrm{CO} 2$ towards the formaldehyde production. Journal of CO2 Utilization 27:179-187 DOI 10.1016/j.jcou.2018.07.014.

Hou C, Hu B, Zhu J. 2018. Photocatalytic degradation of methylene blue over TiO2 pretreated with varying concentrations of $\mathrm{NaOH}$. Catalysts 8(12):575 DOI 10.3390/catal8120575.

Johnsson M, Lemmens P. 2007. Crystallography and chemistry of perovskite. ArXiv preprint. arXiv:cond-mat/0506606.

Kang HW, Park SB. 2010. Water photolysis by natao3-c composite prepared by spray pyrolysis. Advanced Powder Technology 21:106-110 DOI 10.1016/j.apt.2009.11.004.

Kanhere P, Chen Z. 2014. A review on visible light active perovskite based photocatalysts. Molecules 19:19995-20022 DOI 10.3390/molecules191219995. 
Khaneghah SA, Yangjeh AH, Abedi M. 2018. Decoration of carbon dots and $\mathrm{AgCl}$ over g-C3N4 nanosheets: Novel photocatalysts with substantially improved activity under visible light. Separation and Purification Technology 199:64-77 DOI 10.1016/j.seppur.2018.01.023.

Kudo A, Niishiro R, Iwase A, Kato H. 2007. Effects of doping of metal cations on morphology, activity, and visible light response of photocatalysts. The Journal of Chemical Physics 339:104-110 DOI 10.1016/j.chemphys.2007.07.024.

Lan NT, Phan LG, Hoang LH, Huan BD, Hong LV, Anh TX, Chinh HD. 2015. Hydrothermal synthesis, structure and photocatalytic properties of La/BiCo-doped $\mathrm{NaTaO}_{3}$. Materials Transactions 57(1):1-4 DOI 10.2320/matertrans.MA201517.

Langford J, Wilson A. 1978. Scherrer after sixty years: a survey and some results in the determination of crystallite size. Journal of Applied Crystallography 11:102-113 DOI 10.1107/S0021889878012844.

Lavand AB, Malghe YS. 2015. Synthesis, characterization, and visible light photocatalytic activity of nanosized carbon doped zinc oxide. International Journal of Photochemistry 3:305-310 DOI 10.1016/j.jascer.2015.06.002.

Li FF, Liu DR, Gao G. M. Xue B, Jiang YS. 2015. Improved visible-light photocatalytic activity of natao3 with perovskite-like structure via sulfur anion doping. Applied Catalysis B: Environmental 166167:104-111 DOI 10.1016/j.apcatb.2014.10.049.

Li X, Zang J. 2009. Facile hydrothermal synthesis of sodium tantalate nanocubes and high photocatalytic properties. The Journal of Physical Chemistry C 113:19411-19418 DOI 10.1021/jp907334z.

Liu Y, Wang W, Xu X, Veder J-PM, Shao Z. 2019. Recent advances in anion-doped metal oxides for catalytic applications. Journal of Materials Chemistry A 7:7280-7300 DOI 10.1039/C8TA09913H.

Longjie A, Hiroshi O. 2015. Electron-hole recombination controlled by metal doping sites in $\mathrm{NaTaO}_{3}$ photocatalysts. ACS Catalysis 5:3196-3206 DOI 10.1021/acscatal.5b00484.

Momma K, Izumi F. 2011. VESTA 3 for three-dimensional visualization of crystal, volumetric and morphology data. Journal of Applied Crystallography 44:1272-1276 DOI $10.1107 /$ S0021889811038970.

Okoye CMI. 2005. Theoretical investigation of electronic structure and optical properties of paramagnetic non-oxide perovskite alcni3. Solid State Communications 136:605-610 DOI 10.1016/j.ssc.2005.09.033.

PubChem Database. 2008. Sodium tantalate, cid $=23682197$, National Center for Biotechnology Information. Available at https://pubchem.ncbi.nlm.nih.gov/ compound/Sodium-tantalate.

Shi J, Guo L. 2012. Abo3-based photocatalysts for water splitting. Materials International 22(6):592-615 DOI 10.1016/j.pnsc.2012.12.002.

Smith H. 2013. Perovskites: the emergence of a new era for low-cost, high efficiency solar cells. The Journal of Physical Chemistry Letters 4:3623-3630 DOI 10.1021/jz4020162. 
Vishnu S, Saroj LS, Gopal KP, Chandrabhas N, Ashok KG. 2008. Nanocrystalline $\mathrm{NaNbO} 3$ and $\mathrm{NaTaO}_{3}$ : rietveld studies, Raman spectroscopy and dielectric properties. Solid State Sciences 11(2):562-569 DOI 10.1016/j.solidstatesciences.2008.08.001.

Wang B, Kanhere PD, Chen Z, Nisar J, Pathak B, Ahuja R. 2013. Anion-doped $\mathrm{NaTaO}_{3}$ for visible light photocatalysis. The Journal of Physical Chemistry C 117:22518-22524 DOI 10.1021/jp407025r.

Ward K. 2005. Oxidation chemistry of some early transition-metal layered perovskites. Theses and Dissertations, 143, University of New Orleans. Available at https:// scholarworks.uno.edu/td/143.

Wu X, Yin S, Liu B, Kobayashi M, Kakihana M, Sato T. 2014. A carbon modified natao3 mesocrystal nanoparticle with excellent efficiency of visible light induced photocatalysis. Journal of Materials Chemistry A 2(48):20832-20840 DOI 10.1039/C4TA04132A. 